\title{
Action of Trypanosoma rangeli in Infections with Virulent Trypanosoma cruzi Populations
}

\author{
MT Paláu*/+, AJ Mejía*, U Vergara**/***, CA Zúñiga** \\ Laboratorio de Parasitología, Instituto Nacional de Salud, Apartado Postal 80080, Bogotá, Colombia *Departamento de Biología, \\ Facultad de Ciencias, Universidad Nacional de Colombia, Bogotá, Colombia **Unidad de Inmunología, Departamento de \\ Medicina Preventiva, Facultad de Veterinaria ***Escuela de Postgrado, Facultad de Medicina, Universidad de Chile, \\ Santiago, Chile
}

In experimental murine infections with Trypanosoma rangeli it has been observed development immune response to Trypanosoma cruzi. The aim of the present work was to analyze the result of antigenic stimuli and the protective effect with $\mathrm{T}$. rangeli in T. cruzi infections. Mice groups immunized with metacyclic trypomastigotes of $\mathrm{T}$. rangeli (Choachi-2V strain), derived from haemolymph and salivary gland and reinfected with $\mathrm{T}$. cruzi virulent populations (Tulahuen strain, SA strain and Dm28c clone) from infected in vitro cells, showed decrease severity of disease outcomes, low parasitemia levels and $100 \%$ survival of all mice immunized, in comparison with groups infected only with T. cruzi populations, which demonstrated tissue affection, high parasitemia levels and the death of all animals. The above mentioned data contribute to understand the biological behaviour of T. cruzi and T. rangeli and their interaction with vertebrate host.

Key words: Trypanosoma cruzi - Trypanosoma rangeli - protective effect - Chagas disease - parasitemia level

American trypanosomiasis (Chagas disease), caused by the intracellular protozoan Trypanosoma cruzi, is a complicated and devastating disease that affects around 20 million people in Latin America (Miles 1983, Moncayo 1992). Classical transmission to human is by haematophagus triatomine bugs but also by blood transfusions, congenital transplacental, organ transplantation and laboratory accidental infections (Nickerson et al. 1989). Under natural conditions T. cruzi infects in the American continent over 100 mammalian species from different orders, including domestic and sylvatic animals (Teixeira et al. 2001). T. rangeli, an assumed harmless human parasite, uses also a wide variety of mammals host and hemipterous insects in its life cycle (Urdaneta-Morales \& Tejero 1992). It has been postulated that immuno modulating mechanisms induced by $T$. rangeli may have relevance to protection against T. cruzi infection (Saldaña \& Sousa 1996, Zúñiga et al. 1997a).

Murine models are powerful tools for the study of cellular and humoral immunity to T. cruzi and to understand immunological disturbances caused by the infection. Inbred strains of mice may vary from highly resistant to highly susceptible, suggesting a genetic basis for this natural resistance (Hoft et al. 1993) but in neither, the hu-

This work was supported by Instituto Nacional de Salud (Colombia), Colciencias Cód. 2104-04-895-98; Sida/Sarec, Fondecyt/Chile, Agencia Chilena de Cooperación Internacional and Universidad de Chile, Santiago, Chile.

${ }^{+}$Corresponding author. Fax: +56-2-6785605. E-mail: mariapalau99@yahoo.com

Received 30 September 2002

Accepted 7 May 2003 man infection nor the murine model the factors that contribute to resistance or susceptibility have been completely elucidated.

In the present report we have compared the evolution of the $T$. cruzi infection in Balb/c mice inoculated with 10000 trypomastigotes from the Chilean Tulahuen strain, the Colombian SA strain or the Venezuelan clone Dm 28c of the parasite, including a protection study by using preinfection with the Colombian Choachí-2V strain of $T$. rangeli.

\section{MATERIALS AND METHODS}

Mice stocks - Three and 5 weeks old males from Balb/c inbred mouse strain (bred in the colony of Instituto Nacional de Salud, Bogotá, Colombia) were used for experiments.

All animal studies were conducted in accordance with principles and procedures outlined in the International Guiding Principles for Biomedical Research involving Animals (Council for International Organizations of Medical Sciences).

Parasites stocks - The Tulahuen (Pizzi 1957), SA strains, Dm 28c clone (Contreras et al. 1988) of T. cruzi and Choachí-2V strain of T. rangeli were used. The SA strain was isolated in 1999, from Rhodnius pallescenses, in the San Antonio region, Magdalena, Colombia, where an outbreak of acute Chagas disease occurred that year, with several fatal human cases. The Choachí-2V strain was purified by isolation of parasites from haemolymph and salivary glands of $R$. prolixus experimentally infected with parasites from axenic culture.

Cellular infection - Metacyclic parasites from axenic culture of each T. cruzi population, were poured over a semiconfluent layer of Vero cells in Dulbecco's Modified Eagle's Medium (DME) and incubated at $37^{\circ} \mathrm{C}$ overnight. The medium was then discarded, and fresh DME was added. 
Ten days after infection, culture medium was collected and the concentration of live metacyclic trypomastigotes determined by using a hemocytometer.

Vector infection - Thirty fifth instar nymphs of $R$. prolixus maintained in a colony were inoculated by intracelomic route with $2 \mu$ lof exponential growth phase axenic culture of T. rangeli Choachí-2V strain. Then the triatomines were fed on normal mice and maintained under controlled temperature and humidity conditions. Nine days after infection, metatrypomastigotes were collected from haemolymph and salivary glands and then used to infect Balb/c mice.

Infection model - Five weeks-old mice were always used as hosts to $T$. cruzi infection. Groups of 10 mice (5 weeks old), were intraperitoneally infected with 10000 metacyclic trypomastigotes/mouse obtained from Vero cells infected with Tulahuen strain, SA strains or Dm 28c clone of T. cruzi. In addition, a group of 30 mice (3 weeks old) was infected with 10000 trypomastigotes/mouse of T. rangeli Choachí-2V strain trypomastigotes obtained from haemolymph and salivary glands of $R$. prolixus. Two weeks later, when $T$. rangeli parasitemia was negative under microscope observation, separated groups of mice were reinfected with each 1 of the 3 populations of $T$. cruzi.

Mice from each group were sacrificed at different times after infection and their heart and skeletal muscle were subjected to histopathological study to determine presence of parasite pseudocysts and/or tissue damage in 5 $\mu \mathrm{m}$ tissue sections examined by conventional staining with haematoxylyn and eosin. A group of mice, which received only phosphate buffer saline was used as a control.

Parasitemia measurements - Every 2 days, parasitemia levels were analyzed until mice die or they were negative. To determine the presence and amount of parasites, blood samples from each mouse were collected in heparinized microhematocrit capillaries, from caudal vein. After centrifugation and calculating the blood and plasma volumes, capillaries were cut at the division zone between the buffy coat and the red blood cell sediment. The free-swimming bloodstream trypomastigotes, under a $22 \times 22 \mathrm{~mm}$ coverslip, were counted in 50 fields at X 400 magnification (Arias \& Ferro 1988).

\section{RESULTS}

Mice from Balb/c strain were extremely susceptible to the infection with 10000 metacylic trypomastigotes from Tulahuen, SA strains and Dm28c clone of T. cruzi. All mice died within 14 days post-infection (p.i.) when infected with Tulahuen strain, within 12 days p.i. with Dm28c clone and within 18 days p.i. when infected with SA strain of T. cruzi. The mice infected with Choachí-2V strain, from haemolymph and salivary glands of $R$. prolixus, showed $100 \%$ survival after several months p.i., but they had significantly lower parasitemia level than the animals infected with $T$. cruzi parasites. Mice infected with Choachí-2V strain from axenic culture showed scarcity of parasites in circulation (about $10^{4}$ parasites $/ \mathrm{ml}$ ). Fig. 1 shows the evolution of the parasitemia in mice infected with the different parasite populations. The animals infected with Tulahuen and Dm28c clone showed similar maximun parasitemia peak levels of $2.6 \times 10^{5}$ parasites $/ \mathrm{ml}$ (7 days p.i.) and $2.4 \times 10^{5}$ parasites $/ \mathrm{ml}$ ( 9 days p.i.), respectively.

In the mice infected with SA strain maximun parasitemia level found to be only $3.2 \times 10^{4}$ parasites $/ \mathrm{ml}$ (10 days p.i.), but the general state of the mice was bad, with presence of parasites in ascitic fluid. The maximun parasitemia level in mice infected with $T$. rangeli strain was of $1.8 \times 10^{4}$ parasites $/ \mathrm{ml}$.

The mice previously infected with trypomastigotes of T. rangeli Choachí- $2 \mathrm{~V}$ strain and later on reinfected with the different $T$. cruzi populations showed $100 \%$ survival after 6 weeks of reinfection. The levels of parasitemia were very low $\left(10^{3}\right)$ compared with the levels found in the mice infected only with the T. cruzi populations (Fig. 2).

The effect of parasite infection on tissue pathology was evaluated by comparing histopathological study of different tissues obtained at days 5, 10, 12, 20 and 30 p.i. In the first 5 days of infection no significant differences in tissue damage were observed when mice infected with $T$. rangeli were compared with those infected with $T$. cruzi. However, the histopathological study in mice infected with Tulahuen strain and Dm28c clone demonstrated cardiomy-

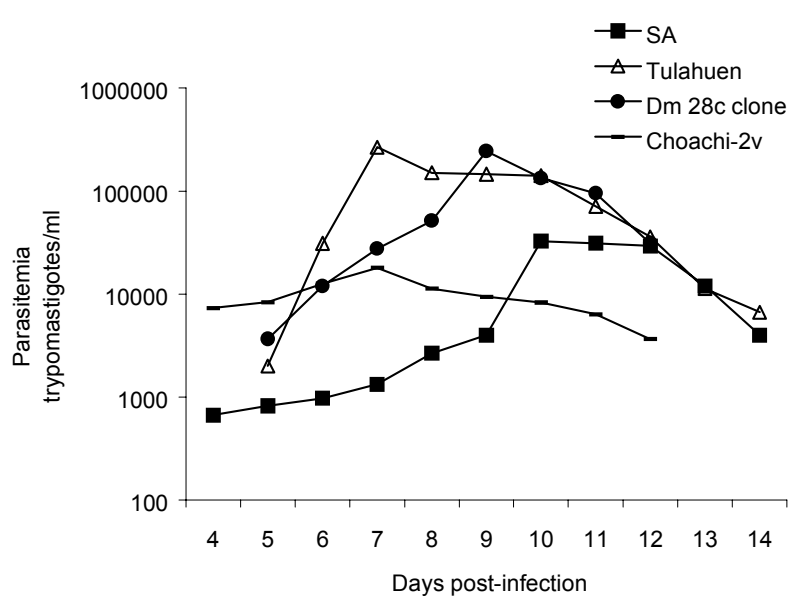

Fig. 1: parasitemia levels expressed as parasites $/ \mathrm{ml}$ in infected mice with Trypanosoma cruzi populations and Trypanosoma rangeli strain. Each point represents the mean parasitemia level in the blood of mice groups $(n=10)$. The graphic is in logarithmic scale.

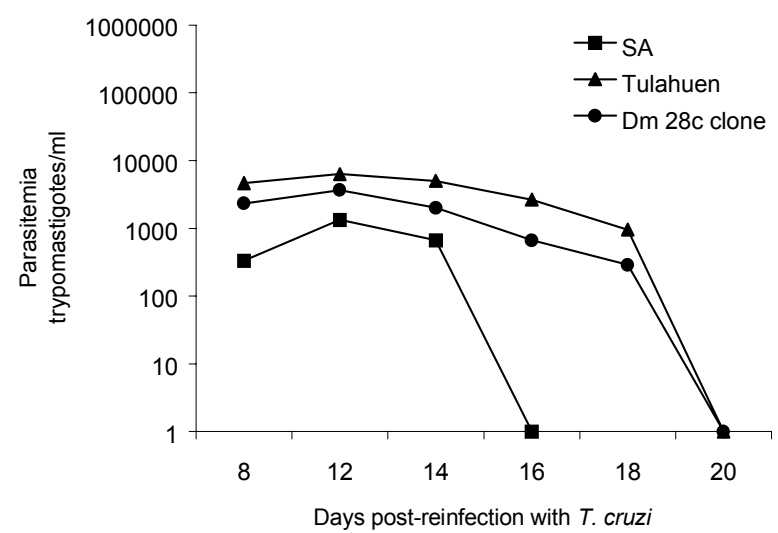

Fig. 2: parasitemia levels in mice group that were infected with Trypanosoma rangeli and reinfected at 15 days with Trypanosoma cruzi populations. The graphic is in logarithmic scale. 
opathy, acute myocarditis and myositis after 10 days p.i. In addition, multiple pseudocysts in cardiac fibers (Fig. 3a) and skeletal muscle were found. As far as the SA strain, we found parasites in intestinal crypts, lym-

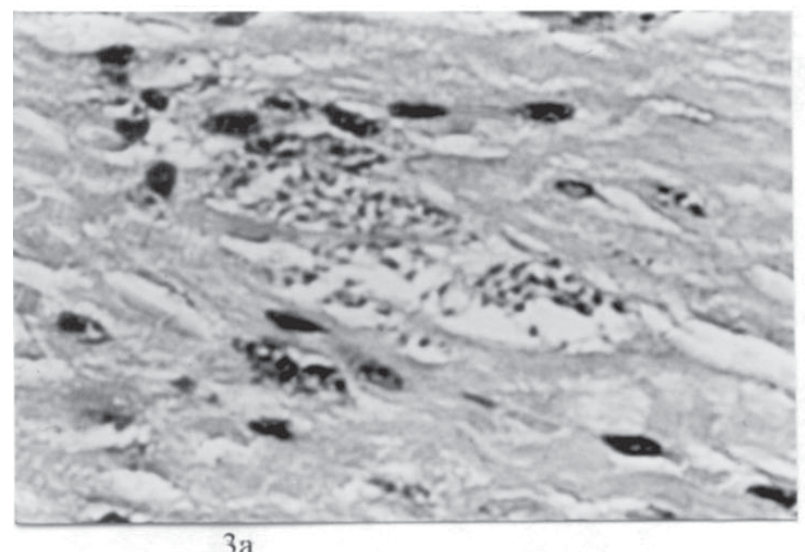

$3 a$

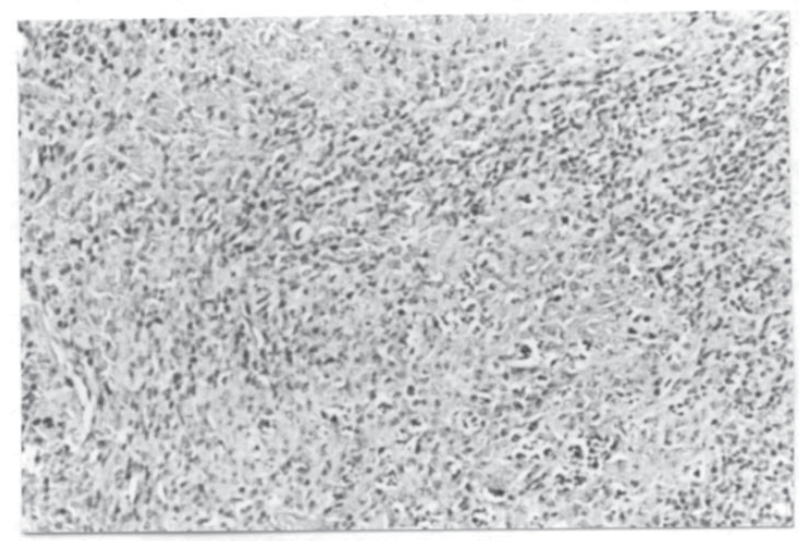

$4 \mathrm{a}$

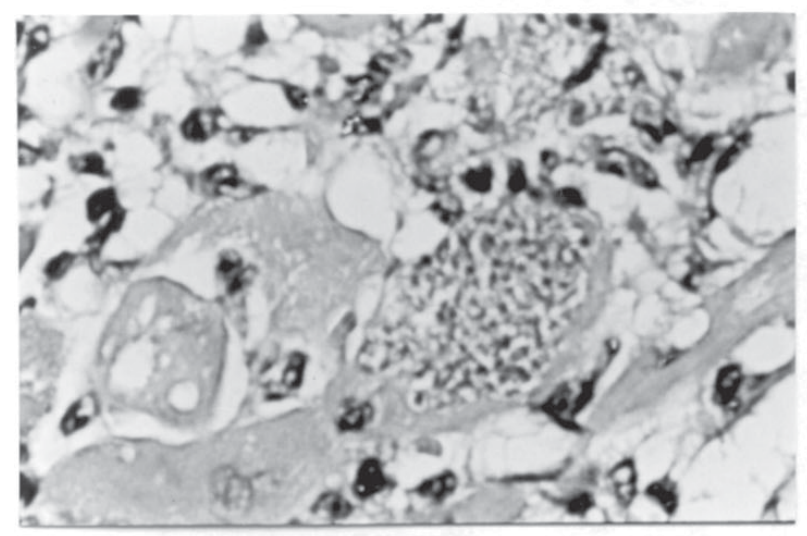

$4 \mathrm{c}$ phoplasmocytic inflammation in skeletal muscles, and amastigote nests and tissue damage in ventricular cardiac fibers (Figs 4a, b, c). In the reinfected groups, we found moderate focal myocarditis without amastigote

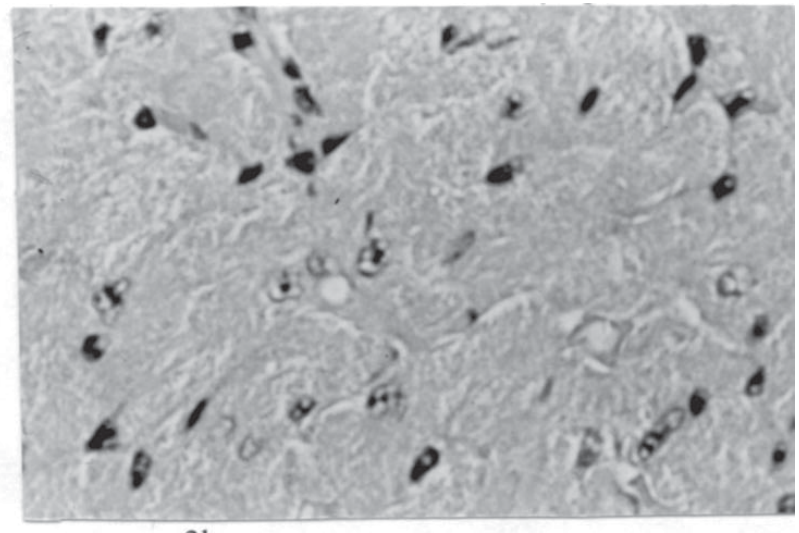

$3 b$

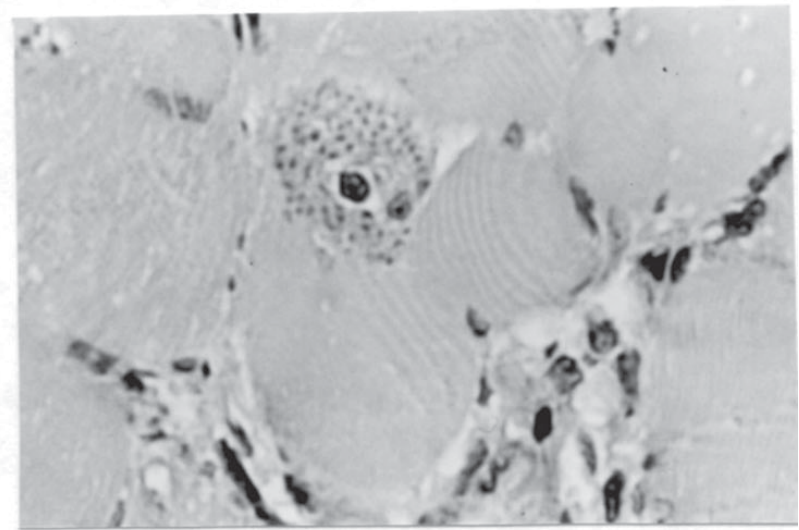

$4 \mathrm{~b}$

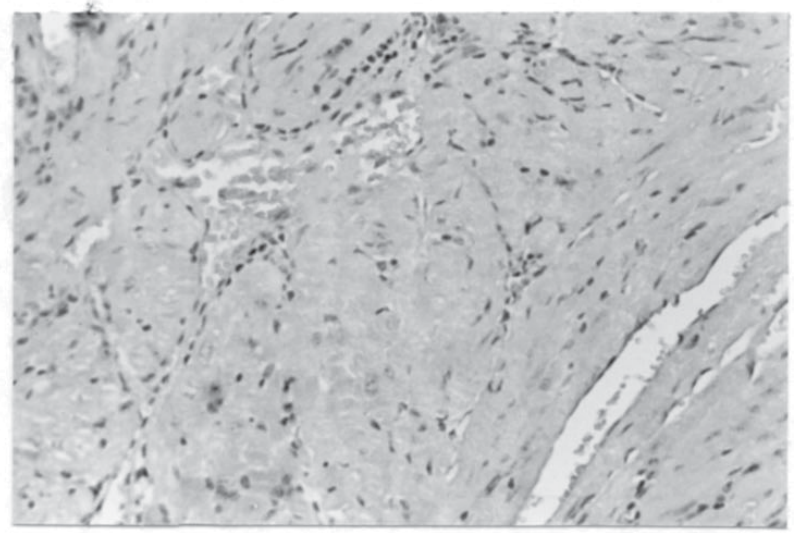

$4 \mathrm{~d}$

Fig. 3a: Tulahuen strain pseudocysts surrounded by leucocyte infiltration with PMN neutrophils, lymphocytes and macrophages. Myocardial tissue section from infected mouse, 12 days p.i. X 400. Fig 3b: mild cellular infiltration among muscle fibers. Myocardial tissue section from Balb/c mouse infected with Trypanosoma rangeli and 15 days later reinfected with Tulahuen strain of Trypanosoma cruzi. Myocardial tissue section from infected mouse, 12 days p.i. X 400. Fig. 4a: infiltration and cellular infiltrate among muscle fibers. Myocardial tissue section from Balb/c mouse with SA strain of T. cruzi, 10 days p.i. X 100. Fig. 4b: mild cellular infiltration among muscle fibers from Balb/c mouse infected with the SA strain of T. cruzi. A pseudocyst is observed in myocardial tissue section from infected mouse, 10 days p.i. X 400. Fig. 4c: detail showing intense acute inflammatory process with PMN neutrophils, lymphocytes and macrophages infiltrate. Disruption of myofibrils and necrosis is observed. Myocardial tissue section of SA infected mouse, 12 days p.i. X 400 . Fig. 4d: cellular infiltration among muscle fibers. Myocardial tissue section from Balb/c mouse infected with T. rangeli and 15 days later reinfected with the SA strain of T. cruzi. Myocardial tissue section from infected mouse, 12 days post-reinfection. X 100. 
nests (Figs 3b, 4d), lymphohistiocytic inflammation in skeletal muscles without parasite presence, and normal liver and spleen. On the other hand, the histopathological study of $T$. rangeli infected mice showed no sign of tissue damage. Failure to detect $T$. rangeli amastigotes in the $5 \mu \mathrm{m}$ tissue sections of the experimentally infected mice could be attributed to the scarcity of intracellular forms and to the possibility that parasites could be localized in lymphoreticular tissues such as bone marrow and lymph nodes, which were not examined in this study.

In summary, mice infected with $T$. cruzi showed fatal chagasic heart disease with increased myocarditis, severe diffuse lesions with mononuclear infiltration, high number of pseudocysts and $100 \%$ mortality. The cellular components of inflammatory infiltrate were predominantly macrophages and lymphocytes with focal infiltration of polymorphonuclear neutrophils (Fig. 4c).

\section{DISCUSSION}

The study of Chagas disease in animal models allowed the definition of a number of distinct mechanisms of pathogenesis, including parasite antigen-specific inflammation, parasite-induced myocardial cell necrosis and repair and autoimmunity (Leon \& Engman 2001).

There is a wide variety in the outcome of T. cruzi infection in mouse models. A mouse strain may develop many different types of disease depending on the virulence of the parasite isolate and a single parasite clone may have very different behaviour in resistant and susceptible mouse strains (Leon \& Engman 2001).

The Tulahuen and SA strains and Dm28c clone of $T$. cruzi studied in this work, have been analyzed in mice groups, with a remarkable maintenance of morphological characteristic of the host-parasite relationship. T. cruzi populations have a clonal structure considered as constitutive units of evolution, which may play a key role in the outcome of Chagas disease (Tibayrenc et al. 1986, Tibayrenc \& Ayala 1991, Montilla et al. 2002). Although our parasite strains may be formed by diverse clones (Dvorak 1984), they probably have a permanent and major clonal composition with stable characteristic.

Relationship between parasitemia and mortality of the mice infected here, showed different patterns for Tulahuen strain and Dm28c clone compared with SA strain of $T$. cruzi. In infections with the Tulahuen strain and Dm28c clone, peak of the parasitemia occurred on the 7 and 9 days p.i. with high number of circulating parasites and all mice died within 12 to 14 days of infection. In contrast, all mice infected with SA strain died around 18-22 days p.i., but they showed low parasitemia level, suggesting that the disease is not a direct result of the parasite amount (Bestetti 1997). This high virulence is uncommon in Colombian strains of T. cruzi. On the other hand, our results are in agreement with previous findings suggesting poor correlation between death and parasitemia level (Wrightsman et al. 1982, Minoprio et al. 1989). Precocious peak of parasitemia and high mortality obtained in Dm28c clone infected mice are different from those obtained in $\mathrm{Balb} / \mathrm{c}$ mice infected with both chemically induced and triatomine-derived metacyclic trypomastigotes (Lopes et al. 1995). However these differences are not unexpected since we have used both younger mice which are higher susceptible to $T$. cruzi infection and more infective trypomastigotes obtained from cell culture supernatant.

The low levels of parasitemia caused by $T$. rangeli and the briefness of its presence in experimental animals (Urdaneta-Morales \& Tejero 1985) have made the study of this parasite difficult. In our hands, the parasitemia level in mice depends on the inoculum origin. Mice infected with parasites obtained from axenic culture showed very low parasitemia levels compared with mice infected with metacyclic trypomastigotes from haemolymph and salivary glands of R. prolixus. Differences with inocula of different origins using C23 strain of T. rangeli has been previously reported (Zúñiga et al. 1997b).

Despite its non-pathogenic characteristics for vertebrate hosts, $T$. rangeli infection induces a humoral immune response resulting in high levels of cross-reactive antibodies with T. cruzi, due to the similarity of their surface antigens (Grisard et al. 1999). On the other hand, mice immunized with fixed $T$. rangeli epimastigotes had significantly lower parasitemias and longer survival than controls when infected with virulent $T$. cruzi trypomastigotes (Basso et al. 1991, Introini et al. 1998).

When T. cruzi strains were challenged here into mice preinfected with $T$. rangeli, mortality decreased and parasitemia was more controlled suggesting that $T$. rangeli is able to induce a strong specific immune response controlling parasitic multiplication in infected individual (Avila \& Rojas 1990, Introini et al. 1998). These results indicate that Choachí-2V strain is a very good antigen for the study of acquired immunity in Chagas disease. In countries where both parasites coexist, the natural exposure to nonvirulent Trypanosoma strains may be involved in the diversity of clinical, pathological and immunological manifestations which occur following infection with the virulent $T$. cruzi strains.

The presence of $T$. rangeli in the same distribution area as T. cruzi in almost all the countries of South and Central America, has been largely considered a serious complication for the Chagas disease diagnosis (Grisard et al. 1999), since false-positive results can be expected from the cross-reactivitiy between both parasites. However, the results presented here suggest that occurrence of single and/or mixed infection in vertebrate hosts may have beneficial effects in evolution and epidemiology of Chagas disease. Protection against T. cruzi infection was induced by pre-infection with T. rangeli parasites. Peak parasitemia in pre-infected mice was significantly reduced and the animals were negative until at least 60 days p.i. The severity of tissue damage was clearly diminished and mice survived to infection. Therefore, the possibility that concomitant infection on endemic areas mask or naturally protect people from the development of severe symptoms of Chagas disease can not be excluded.

The use of different $T$. cruzi parasites, with distinct tissue tropism and virulence, may influence the type of effector response by selecting distinct $T$ cell subsets with varying cytokines profiles (Rottenberg et al. 1988, Tarleton 1990, Tarleton et al. 1992). Therefore, although the immune mechanisms responsible for the resistance to T. cruzi infection are still unclear, innate and acquired humoral 
and cellular immune response might be exacerbated in the T. rangeli pre-infected mice. We presumed that parasitespecific immunity is already operative in the 15 days of lag time difference between the T. rangeli and T. cruzi infections since $T$. cruzi-specific antibodies and delayed type hypersensitivity develop within 2 weeks during acute infection of $\mathrm{A} / \mathrm{J}$ mice with the Brazil strain of the parasite (Leon \& Egman 2001). During invasion of the host, the parasites expose functional molecules that become targets for the host immune response and may contribute to the killing of the parasite. Among these molecules, the several members of the Shed Acute Phase Antigen/Transsialidase/Neuraminidase (SAPA/TS/NS) protein family and the core protein of the mucin-like glycoprotein expressed in the bloodstream trypomastigotes are involved in both generating an immune response and helping to establish the parasite infection (Frasch 1994, 2000). The trans-sialidase, which is located in the surface membrane of $T$. cruzi and is also shed into the medium, enables the parasite to invade host cells by transferring sialyl residues from host glycoconjugates to the abundant mucinlike acceptor molecules on the parasite surface. Once sialylated, the acceptor glyconjugates seem to be involved in binding and invasion of the host cells by the parasite and in the protection against the alternative complement pathway (Ruiz et al. 1993, Schenkman et al. 1991, Tomlinson et al. 1994).

Antibodies recognizing the parasite mucins (Pollevick et al. 2000) and those neutralizing the trans-sialidase activity have been found in sera from T. cruzi infected humans and animals (Leguizamón et al. 1994a, b). Therefore, we can speculate that cross-reactive antibodies induced by the homologous mucins and sialidases expressed in $T$. rangeli might be involved in the protective effect of $T$. rangeli infection on evolution of Chagas disease.

The $T$. cruzi SAPA/TS/NS molecules are characterized by the presence of a carboxy-terminal domain made up of a variable number of tandemly repeated 12 aminoacid-long units (SAPA repeats) and a non-repeated amino-terminal domain containing the enzymatic activity. SAPA repeats are not required for trans-sialylation, but are necessary to maintain the enzyme active in circulation in the blood and to stimulate the production of antibodies against the catalytic domain that inhibits the trans-sialidase activity of the molecule (Buscaglia et al. 1998). T. rangeli expresses a sialidase, $70 \%$ identical in sequence to the $T$. cruzi enzyme but it lacks the SAPA repeats extension and is completely devoid of trans-sialylation activity (Buschiazzo et al. 1997). However, since a few aminoacid differences around the active site of $T$. rangeli sialidase and the $T$. cruzi trans-sialidase confer the transglicosylation activity (Buschiazzo et al. 2000), we can not exclude the possibility that antibodies against cross-reacting epitopes within the $T$. rangeli sialidase neutralize the enzymatic activity of the T. cruzi trans-sialidase.

In summary, the results presented here have demonstrated that $\mathrm{Balb} / \mathrm{c}$ mice infected with T. rangeli are protected against lethal infection by virulent $T$. cruzi trypomastigotes. The minimal to discrete inflammatory tissue infiltrate in absence of parasites observed in protected animals is not unexpected since as suggested by others
(Younés-Chennoufi et al. 1988, Guarner et al. 2001), the antigenic stimulation might persists throughout the chronic phase even though the parasites are not morphologically detectable.

\section{ACKNOWLEDGEMENTS}

To Marleny Montilla for helping us with nymph inoculations, to María Mercedes Santacruz for collaborating in preliminary assays, to Pathology Group for the histopathology, to Cristina Ferro for providing Rhodnius prolixus nymphs, to Santiago Nicholls and Carlota Arteaga for contribution and collaboration, all of them are members of Instituto Nacional de Salud, Bogotá (Colombia).

\section{REFERENCES}

Arias AR, Ferro EA 1988. Quantification of Trypanosoma cruzi parasitemia by direct micromethod. Trans $R$ Soc Trop Med Hyg 82: 248.

Avila JL, Rojas M 1990. Elevated cerebroside antibody levels in human visceral and cutaneous leishmaniasis, Trypanosoma rangeli infection and chronic Chagas disease. $\mathrm{Am} \mathrm{J}$ Trop Med Hyg 43: 52-60.

Basso B, Moretti E, Vottero-Cima E 1991. Immune response and Trypanosoma cruzi infection in Trypanosoma rangeli immunized mice. Am J Trop Med Hyg 44: 413-419.

Bestetti RB 1997. Should benznidazole be used in chronic Chagas disease? (letter; comment). Lancet 349: 653.

Buscaglia CA, Campetella OE, Leguizamón, Frasch AC 1998. The repetitive domain of Trypanosoma cruzi trans-sialidase enhances the immune response against the catalytic domain. J Infect Dis 177: 431-436.

Buschiazzo A, Campetella OE, Frasch AC 1997. Trypanosoma rangeli sialidase: cloning, expression and similarity to $T$. cruzi trans-sialidase. Glycobiology 7: 1167-1173.

Buschiazzo A, Tavares GA, Campetella OE, Spinelli S, Cremona ML, París G, Amaya MF, Frasch ACC, Alzari PM 2000. Structural basis of sialyltransferase activity in trypanosomal sialidases. EMBO J 19: 16-24.

Contreras VT, Araujo-Jorge T, Bonaldo M, Thomaz N, Barbosa H, Meirelles M, Goldenberg S 1988. Biological aspect of the Dm 28c clone of Trypanosoma cruzi after metacyclogenesis in chemically defined media. Mem Inst Oswaldo Cruz 83: 123-133.

Dvorak JA 1984. The natural heterogeneity of Trypanosoma cruzi: biological and medical implications. J Cell Biochem 24: 357-371.

Frasch AC 1994. Trans-sialidase, SAPA amino acid repeats and the relationship between Trypanosoma cruzi and the mammalian host. Parasitology 108: S37-S44.

Frasch AC 2000. Functional diversity in the trans-sialidase and mucin families in Trypanosoma cruzi. Parasitol Today 16: 282-286.

Grisard EC, Steindel M, Guarneri AA, Eger-Mangrich I, Campbell DA, Romanha AJ 1999. Characterization of Trypanosoma rangeli strains isolated in Central and South America: an overwiev. Mem Inst Oswaldo Cruz 94: 203209.

Guarner J, Bartlett J, Zaki SR, Colley DG, Grijalva MJ, Powell MR 2001. Mouse model for Chagas disease: immunohistochemical distribution of different stages of Trypanosoma cruzi in tissues throughout infection. Am J Trop Med Hyg 65: 152-158.

Hoft DF, Lynch R, Kirchoff L 1993. Kinetics analysis of antigen-specific immune response in resistant and susceptible mice during infection with Trypanosoma cruzi. $J$ Immunol 151: 7038-7047. 
Introini MV, Basso B, Moretti E 1998. Experimental Chagas disease. I Study of different inmunization conditions in the infection course. Bol Chil Parasitol 53: 45-51.

Leguizamón SM, Campetella OE, González Cappa SM, Frasch AC 1994a. Mice infected with Trypanosoma cruzi produce antibodies against the enzymatic domain of trans-sialidase that inhibit its activity. Infect Immun 62: 3441-3446.

Leguizamón SM, Campetella OE, Russomando M, Amiron I, Guillen S, González Cappa SM, Frasch AC 1994b. Antibodies inhibiting Trypanosoma cruzi trans-sialidase activity in sera from human infections. J Infect Dis 170: 1570-1574.

Leon JS, Engman DM 2001. Autoimmunity in Chagas heart disease. Int J Parasitol 31: 555-561.

Lopes MF, Cunha JMT, Bezerra FL, Gonzalez MS, Gomes JEL, Lapa e Silva JR, Garcia ES, Dos Reis GA 1995. Trypanosoma cruzi: both chemically induced and triatomine-derived metacyclic trypomastigotes cause the same immunological disturbance in the infected mammalian host. Exp Parasitol 80: 194-204.

Miles MA 1983. The epidemiology of South American trypanosomiasis: biochemical and immunological approaches and their relevance to control. Trans R Soc Trop Med Hyg 77: 5-23.

Minoprio P, Itohara S, Heusser C, Tonegawa S, Coutinho A 1989. Immunobiology of murine T. cruzi infection: the predominance of parasite-nonspecific responses and the activation of TCRI cells. Immunol Rev 112: 183-207.

Moncayo A 1992. Chagas disease: epidemiology and prospects for interruption of transmission in the Americas. Wld Hlth Statist Quant 45: 276-279.

Montilla M, Guhl F, Jaramillo C, Nicholls S, Barnabe C, Bosseno M, Breniere S 2002. Isoenzyme clustering of Trypanosomatidae Colombian populations. Am J Trop Med Hyg 66: 394-400.

Nickerson P, Orn P, Schroeder M, Sekla L, Johnston J 1989. Transfusion associated Trypanosoma cruzi infection. Ann Inter Med 111: 851-853.

Pizzi TP 1957. Inmunología de la Enfermedad de Chagas, Universidad de Chile, Santiago, p. 18.

Pollevick GD, Di Noia JM, Salto ML, Lima C, Leguizamón MS, de Lederkremer RM, Frasch AC 2000. Trypanosoma cruzi surface mucins with exposed variant epitopes. J Biol Chem 275: 27671-27680.

Rottenberg M, Cardoni RL, Anderson R, Segura EL, Orn A 1988. Role of T helper/inducer cells as well as natural killer cells in resistance to Trypanosoma cruzi infection. Scand J Immunol 28: 573-582.

Ruiz R, Riggoni VL, González J, Yoshida N 1993. The 35/50 $\mathrm{kDa}$ surface antigen of Trypanosoma cruzi metacyclic trypomastigotes, an adhesion molecule involved in hods cell invasion. Parasite Immunol 15: 121-125.
Schenkman S, Jiang MS, Hart GW, Nussenzweig V 1991. A novel cell surface trans-sialidase of Trypanosoma cruzi generates a stage-specific epitope required for invasion of mammalian cells. Cell 65: 1117-1126.

Saldaña A, Sousa OE 1996. Trypanosoma rangeli and Trypanosoma cruzi: cross-reaction among their immunogenic components. Mem Inst Oswaldo Cruz 91: 81-82.

Tarleton RL 1990. Depletion of CD8+ T cells increase susceptibility and reverses vaccine-induced immunity in mice infected with Trypanosoma cruzi. J Immunol 144: 717-724.

Tarleton RL, Kohler BH, Latour A, Postan M 1992. Susceptibility of beta 2-microglobulin-deficient mice in murine Chagas disease. Nature (London) 356: 338-341.

Teixeira A, Sadi P, Rebelo E, Algarañaz D, Vieira L, Lauria-Pires L, Nascimento R, Vexenant A, Silva A, Ault S, Costa J 2001. Emerging Chagas disease: trophic network and cycle of transmission of Trypanosoma cruzi from palm threes in the Amazon. Emerg Infect Dis 1: 100-112.

Tibayrenc M, Ayala FJ 1991. Towards a population genetics of microorganism: the clonal theory of parasitic protozoa. Parasitol Today 7: 228-232.

Tibayrenc M, Ward P, Moya A, Ayala FJ 1986. Natural populations of Trypanosoma cruzi, the agent of Chagas disease have a complex multiclonal structure. Proc Natl Acad Sci USA 83: 115-119.

Tomlinson S, Pontes de Carvaho LC, Vanderkerckhove F, Nussenzweig V 1994. Role of sialic acid in the resistance of Trypanosoma cruzi trypomastigotes to complement. $J$ Immunol 153: 3141-3147.

Urdaneta-Morales S, Tejero F 1985. Trypanosoma (Herpetosoma) rangeli Tejera 1920: mouse model for high sustained parasitemia. J Parasitol 4: 409414.

Urdaneta-Morales S, Tejero F 1992. Trypanosoma rangeli (Tejera 1920): observations upon pleomorphism. Mem Inst Oswaldo Cruz 87: 511-516.

Wrightsman R, Krassner S, Watson J 1982. Genetic control of response to Trypanosoma cruzi in mice: multiple genes influencing parasitemia and survival. Infect Immun 36: 637644.

Younés-Chennoufi AB, Hontebeyrie-Joskowicz M, Tricottet V, Eisen H, Reynes M, Said G 1988. Persistence of Trypanosoma cruzi antigens in the inflammatory lesions of chronically infected mice. Trans $R$ Soc Trop Med Hyg 82: 77-83.

Zúñiga C, Paláu MT, Penin P, Gamallo C, De-Diego JA 1997a. Protective effect of Trypanosoma rangeli against infections with a highly virulent strain of Trypanosoma cruzi. Trop Med Int Health 5: 482-487.

Zúñiga C, Paláu MT, Penin P, Gamallo C, De-Diego JA 1997b. Trypanosoma rangeli: increase in virulence with inocula of different origins in the experimental infection in mice. Parasitol Res 83: 797-800. 